\title{
BMJ Open Addressing maternal and child health equity through a community health worker home visiting intervention to reduce low birth weight: retrospective quasi-experimental study of the Arizona Health Start Programme
}

\author{
Samantha Sabo (1) , ${ }^{1}$ Patrick Wightman, ${ }^{2}$ Kelly McCue (D) , ${ }^{1}$ Matthew Butler, ${ }^{3}$ \\ Vern Pilling, ${ }^{4}$ Dulce J Jimenez (D) , ${ }^{1}$ Martín Celaya, ${ }^{5}$ Sara Rumann ${ }^{5}$
}

To cite: Sabo S, Wightman $P$, McCue K, et al. Addressing maternal and child health equity through a community health worker home visiting intervention to reduce low birth weight: retrospective quasi-experimental study of the Arizona Health Start Programme. BMJ Open 2021;11:e045014. doi:10.1136/ bmjopen-2020-045014

- Prepublication history and supplemental material for this paper is available online. To view these files, please visit the journal online (http://dx.doi. org/10.1136/bmjopen-2020045014).

Received 19 September 2020

Revised 09 April 2021

Accepted 12 April 2021

A Check for updates

(C) Author(s) (or their employer(s)) 2021. Re-use permitted under CC BY-NC. No commercial re-use. See rights and permissions. Published by BMJ.

For numbered affiliations see end of article.

Correspondence to Dr Samantha Sabo; samantha.sabo@nau.edu

\section{ABSTRACT}

Objective To test if participation in the Health Start Programme, an Arizona statewide Community Health Worker ( $\mathrm{CHW}$ ) maternal and child health (MCH) home visiting programme, reduced rates of low birth weight (LBW), very LBW (VLBW), extremely LBW (ELBW) and preterm birth (PTB).

Design Quasi-experimental retrospective study using propensity score matching of Health Start Programme enrolment data to state birth certificate records for years 2006-2016.

Setting Arizona is uniquely racially and ethnically diverse with comparatively higher proportions of Latino and American Indian residents and a smaller proportion of African Americans.

Participants 7212 Health Start Programme mothers matched to non-participants based on demographic, socioeconomic and geographic characteristics, health conditions and previous birth experiences.

Intervention A statewide $\mathrm{CHW} \mathrm{MCH}$ home visiting programme.

Primary and secondary outcome measures LBW, VLBW, ELBW and PTB.

Results Using Health Start Programme's administrative data and birth certificate data from 2006 to 2016, we identified 7212 Health Start Programme participants and 53948 matches. Programme participation is associated with decreases in adverse birth outcomes for most subgroups. Health Start participation is associated with statistically significant lower rates of LBW among American Indian women (38\%; average treatment-on-the-treated effect (ATT): $2.30 ; 95 \% \mathrm{Cl}-4.07$ to -0.53 ) and mothers with a pre-existing health risk (25\%; ATT: $-3.06 ; 95 \% \mathrm{Cl}$ -5.82 to -0.30 ). Among Latina mothers, Health Start Programme participation is associated with statistically significant lower rates of VLBW (36\%; ATT: $0.35 ; 95 \% \mathrm{Cl}$ -0.69 to -0.01$)$ and ELBW (62\%; ATT: $0.31 ; 95 \% \mathrm{Cl}(-0.52$ to -0.10$)$ ). Finally, Health Start Programme participation is associated with a statistically significant lower rate of PTB for teen mothers (30\%; ATT: $2.81 ; 95 \% \mathrm{Cl}-4.71$ to -0.91$)$. Other results were not statistically significant.
Strengths and limitations of this study

- The large sample sizes of the intervention and comparison groups enabled calculation of more reliable estimates of the Health Start Programme's effect with respect to relatively rare and infrequent outcomes for the programme as a whole and for select demographic subgroups.

- The primary limitation is the identifying assumption (common to all propensity-score matching analyses) that participation in the Health Start Programme is fully explained by observable characteristics.

- The analysis may have limited external validity for populations that differ along socioeconomic status, race and ethnicity.

- The study design and limited information on programme implementation mean the present study is not able to identify which specific programmatic features are associated with outcomes we find.

Conclusion A state health department-operated $\mathrm{MCH}$ home visiting intervention that employs $\mathrm{CHWs}$ as the primary interventionist may contribute to the reduction of LBW, VLBW, ELBW and PTB and could improve birth outcomes statewide, especially among women and children at increased risk for $\mathrm{MCH}$ inequity.

\section{INTRODUCTION}

Growing maternal and child health (MCH) inequities are largely associated with multilevel social and structural determinants of health, many of which are beyond the proximal control of any individual or community. ${ }^{12}$ Here, we focus on low birth weight (LBW), very LBW (VLBW) and extremely LBW (ELBW), generally accepted to be a result of preterm birth (PTB) or fetal growth restriction $^{34}$ and associated with several interlocking 


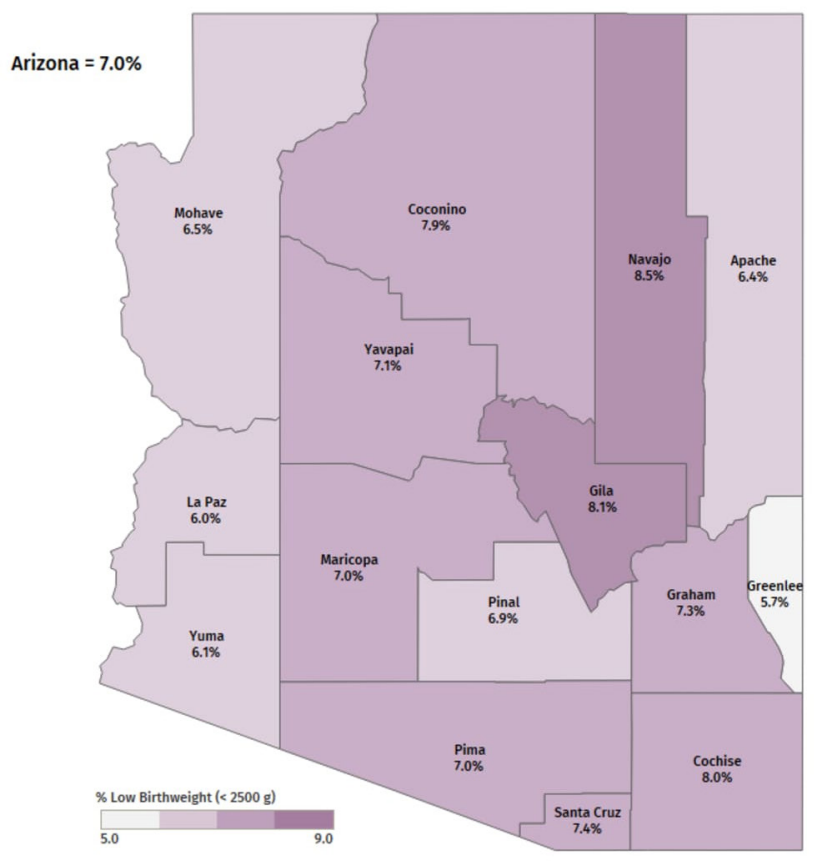

Figure 1 Low birth weight (LBW) in Arizona, 2010-2016. Map demonstrates the per cent of LBW, defined as <2500 g, by county of maternal residence in Arizona. Map courtesy of and permission by Arizona Health Start Programme, Arizona Department of Health Services. This map is not under copyright.

socioecological risk factors, including poverty, discrimination and access and quality of care among others. ${ }^{5}$ Rates of LBW, VLBW and ELBW in the USA consistently track with socioeconomic and ethnoracial health inequities. ${ }^{6}$ Women and children of colour, specifically African American, Latina and American Indian communities, experience disproportionally higher rates of LBW and $\mathrm{VLBW}^{78}$ (figures 1-3).

At the individual level, LBW, VLBW, ELBW and PTB are influenced by several behaviours associated with living in poverty and experiencing personally and institutionally mediated racism and discrimination, including smoking, ${ }^{9}$ poor nutrition, ${ }^{10}$ acute stress, ${ }^{11}{ }^{12}$ prenatal depression ${ }^{1314}$ and late or no prenatal care. Such factors may be exacerbated by interpersonal relationships, short interpregnancy intervals,${ }^{15}$ relationship stress,${ }^{11}$ interpersonal violence ${ }^{12}$ and lack of social support. ${ }^{12}$ It is widely accepted that societal-level influences, including exposure to discrimination, ${ }^{12}$ living in disadvantaged neighbourhoods, ${ }^{16}$ experiencing low socioeconomic status $(\mathrm{SES})^{12}$ and lacking access to health insurance, ${ }^{12}$ all contribute to the cumulative physiological damage on the body caused by environmental stressors. ${ }^{17}$ From a life course perspective, LBW, VLBW, ELBW and PTB have several implications for health equity, including cost of care, ${ }^{18}$ decreased long-term educational attainment and earnings, and the predisposition for adult-onset chronic diseases. ${ }^{19-21}$ Furthermore, documented differences in birth weight and SES in the US compound health equity through observed correlations in economic standing across generations. ${ }^{22}$

For more than half a century, community health workers (CHWs) have served as trusted members of communities experiencing health inequity, defined as the unfair and preventable differences in health and wellbeing. ${ }^{23}$ As a workforce, CHWs are trusted intermediaries between people and systems and are consistently effective within clinical-based and community-based contexts and with high priority health issues such as managing chronic diseases, improving birth outcomes and maintaining child wellness. ${ }^{23}{ }^{24}$ Among national expansion of state and tribal health departments, Medicaid services, health plans and provider groups that promote CHW integration, ${ }^{25}$ CHWs have emerged as a healthcare workforce able to enhance the patient experience of care, improve population health, reduce cost of care and improve the experience of providing care among clinicians and staff. ${ }^{26} 27$

While early childhood home visitation has a goal of improving birth outcomes, studies using random assignment have seen significant challenges in doing so, even with registered nurses as the home visitors. ${ }^{28} \mathrm{We}$ conducted a quasi-experimental evaluation of a longstanding state health department-operated programme administered within county, clinic and community-based organisations in 14 rural and urban counties across Arizona to assess whether Health Start Programme participation is associated with improved birth and birth-related outcomes. ${ }^{29}$ Our study aims to contribute to the gap in 
Very Low Birthweight (< 1500 g) per 1,000 Live Births by County of Maternal Residence, 2010-2016

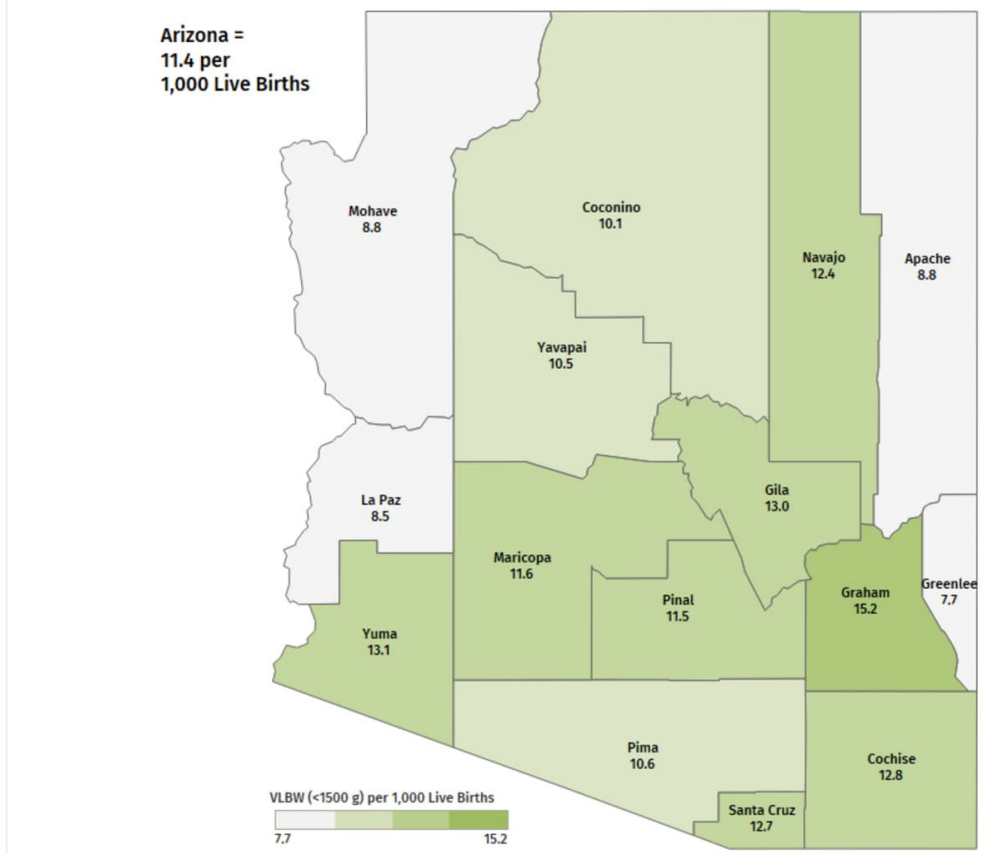

2020 Maphox OPenstreetmap

Figure 2 Very low birth weight (VLBW) in Arizona, 2010-2016. Map demonstrates the incidence of VLBW, defined as $<1500$ g, per 1000 live births by county of maternal residence in Arizona. Map courtesy of and permission by Arizona Health Start Programme, Arizona Department of Health Services. This map is not under copyright.

Percent Preterm Births (<37 weeks) by County of Maternal Residence, 2010-2016

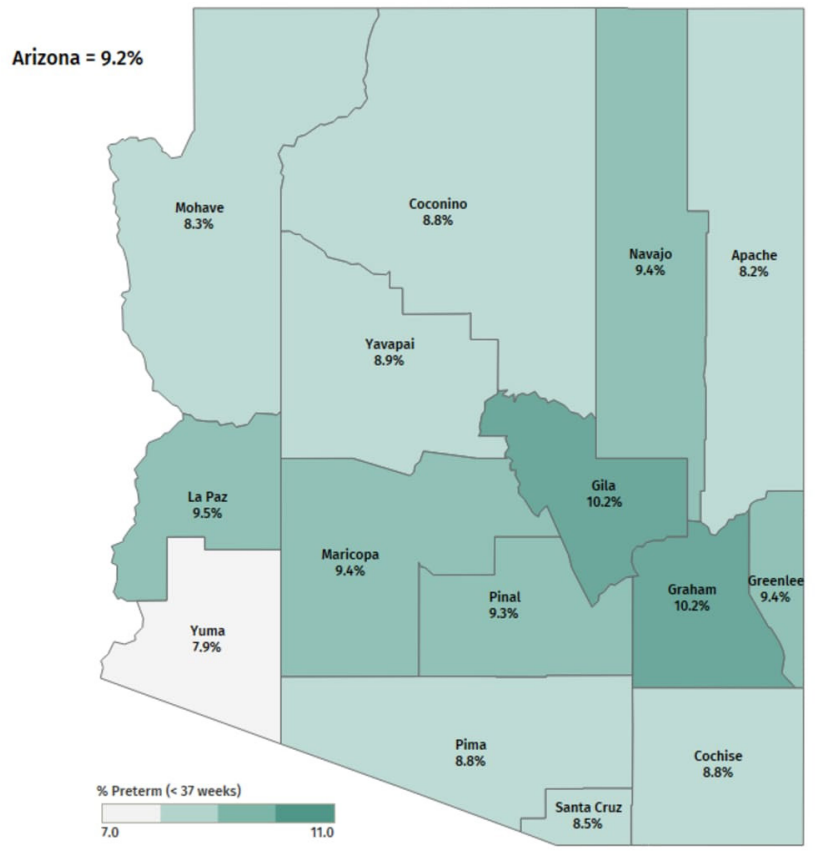

Figure 3 Preterm births (PTBs) in Arizona, 2010-2016. Map demonstrates the per cent of PTBs, defined as $<37$ weeks of gestation, by county of maternal residence in Arizona. Map courtesy of and permission by Arizona Health Start Programme, Arizona Department of Health Services. This map is not under copyright. 
literature for rigorous evaluations of CHW-led home visiting programmes targeting MCH equity.

Established in 1994, the Arizona Health Start Programme is a primary prevention home visitation intervention aimed at improving $\mathrm{MCH}$ outcomes among medically and socially high risk, racially and ethnically diverse, rural and urban mothers with children aged 0-2 years. ${ }^{30}{ }^{31} \mathrm{MCH}$ home visiting services are delivered by trained CHWs who, through CHW core competency and specialised $\mathrm{MCH}$ training, connect clients to prenatal care and increase continuity of care during and after pregnancy. ${ }^{29}$ Broadly, CHWs identify, screen and enrol eligible women; provide perinatal and postpartum education and social support; provide referral and advocacy services; and emphasise timely immunisations and developmental assessments for children. ${ }^{29} 3132$ During pregnancy, CHWs provide education (eg, perinatal nutrition, physical symptoms and changes, labour and delivery, and breastfeeding); assist with access and enrolment to continuous perinatal care; screen, educate and follow-up for maternal behavioural health disorders, alcohol, tobacco and drug cessation; and intimate partner violence. The Health Start Programme's CHWs are trained to motivate and support their clients through behaviour change activities that promote personal agency and self-efficacy, and achieve Health Start Programmatic goals, including reducing LBW outcomes.

This paper is part of a broader research agenda assessing the impact of the Arizona Health Start Programme on newborn health, maternal healthcare utilisation and early child health. The specific objective of the analysis presented here is to assess the effectiveness of the Health Start Programme with respect to newborn health, particularly whether participation is associated with lower rates of LBW, VLBW, ELBW and PTB compared with non-participating women. Our methodological strategy is explicitly motivated and guided by Home Visiting Evidence of Effectiveness (HomVEE) standards, established by the US Department of Health and Human Services. ${ }^{33}$

This evaluation builds on a previous assessment of the Health Start Programme, which found that programme participation was associated with a reduction in the likelihood of LBW. ${ }^{31}$ Accordingly, our primary hypothesis is that mothers and children that participated in this MCH home visitation programme during the study period of 2006-2016 will experience lower rates of LBW, VLBW, ELBW and PTB.

\section{METHODS}

\section{Study design and data}

This study uses a quasi-experimental design to estimate the impact of Health Start Programme participation on LBW, VLBW, ELBW and PTB. All data on births and mothers are derived from Arizona's Vital Records Birth Database, maintained by the Arizona Department of Health Services for the years 2006-2016. This information was linked to Health Start Programme enrolment data to identify participants. Both the Health Start Programme enrolment information and birth certificate records are administrative data sources, established and maintained primarily for public health monitoring. Detailed Health Start Programme evaluation protocol, including the process used to merge the birth certificate records and Health Start Programme enrolment data, Health Start intervention components, and CHW training is published elsewhere. $^{29}$

\section{Outcomes}

The primary outcomes of our study are LBW, birth weight less than $2500 \mathrm{~g}$ despite gestational age; VLBW, birth weight less than $1500 \mathrm{~g}$; ELBW, birth weight less than $1000 \mathrm{~g}$; and PTB, a gestational age of less than 37 completed weeks of pregnancy.

\section{Patient and public involvement}

Patients and the public were not involved in the design or conducting and reporting of the study.

\section{Study population}

Women can enrol in Health Start Programme during pregnancy and/or if they have a child of 2 years of age or younger and can remain in the programme as long as they maintain this criterion. Non-pregnant women enrolling with children who are 2 years of age or younger still receive home visits and preconception and interconception health education, which is associated with improved birth outcomes. ${ }^{28}{ }^{34}$ We limited the treatment population to women who were enrolled prior to giving birth to the children whose birth certificates comprise our data source. This resulted in 7212 Health Start Programme-attributed births and 53948 matches from a total of 966809 non-Health Start Programme's births statewide (table 1). Approximately $13 \%$ of the Health Start Programme population were enrolled in the programme between 9 months and 15 months prior to the birth of the target child, due to previous programme eligibility.

\section{Intervention group}

A detailed description of the protocol used to link Health Start Programme enrolment records to birth certificate records can be found elsewhere. ${ }^{29}$ Briefly, Health Start Programme administrative data were curated to create a longitudinal panel of all Health Start Programme enrollees, which was queried against the Arizona Department of Health Services Vital Records Birth Database using a combination of first name, last name and date of birth. The final linked dataset included an internally generated random unique identifier, measures of linkage quality, the mother's Health Start Programme enrolment date and the child's birth date.

\section{Propensity score matching and synthetic control groups}

To limit bias in our estimate of the effectiveness of the Health Start Programme, we followed HomVEE guidelines for observational/retrospective evaluations. 
Table 1 Matching results (baseline equivalence) for statewide and rural border county HSP participants

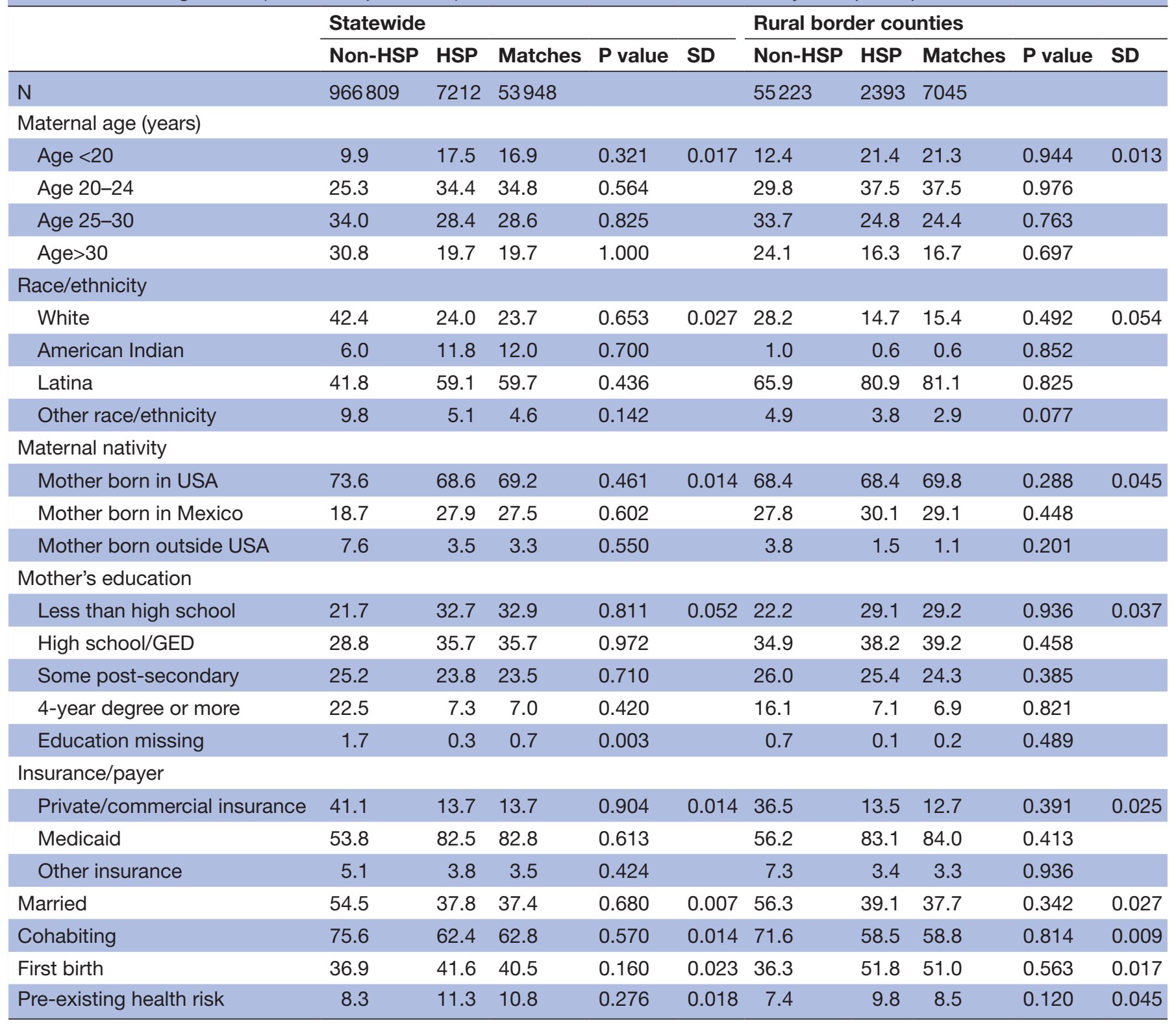

Matches: comparison group identified via propensity score. All models control for median income at the zip code level, county of residence and year of birth. Participant subgroups matching models may include additional interactions between controls in order to achieve baseline equivalence. Full tables available upon request.

GED, general education development test; HSP, Health Start Programme; SD, standardised difference.

Specifically, we generated a synthetic control group via propensity score matching, using information provided in birth certificate records. Propensity score matching is used to estimate counterfactual outcomes for a given treatment, that is, what would have happened in the absence of treatment. Matching methods are quasiexperimental, mimicking treatment-control group study designs by identifying a comparison group that is statistically similar to the treatment group. Treatment effectiveness is measured by the difference in outcomes between the two groups, sometimes referred to as the average treatment-on-the-treated effect (ATT).
The 'propensity score' is the parameter used to identify the control group and is typically the estimated probability (propensity) that a given individual is part of the treatment group, based on the individual's characteristics. For this analysis, the propensity scores used to identify each mother's nearest statistical neighbour were estimated via logistic regression. We allowed for multiple nearest-neighbour matches (ie, ties) to the same Health Start Programme (treatment) observation, based on the estimated propensity score. Thus, the population rates among the matched control groups, for both the covariates used in the matching model 
and the outcome measures, are the weighted averages across all matches.

Control group candidates were first limited to mothers residing within the same geographic regions and who gave birth within the same calendar years as the Health Start Programme participants, to implicitly account for prevailing economic and policy conditions based on time and location, as well as any programme parameters that may have shifted as Health Start Programme developed over the study period.$^{35}$ Next, we selected variables for the matching model itself, which was complicated because Arizona revised the birth certificate form in 2014. As a result, some variables were constructed from component fields (on either side of the revision) in order to generate consistent measures. The final roster of controls were chosen based on their association with both treatment status (ie, Health Start Programme participation) and the outcomes of interest. ${ }^{36}$ Because Health Start Programme eligibility focuses largely on social and medical risks, we prioritised inclusion of related birth certificate fields. Additionally, in order to achieve an evidence-based rating of 'Moderate', the highest rating for which matched comparison group study designs are eligible, ${ }^{33}$ HomVEE requires (at the time of this writing) at least two direct measures of SES. We used maternal education (less than high school, high school, some college, 4 years or more of post-secondary education) and the mother's primary insurance payer (private/commercial, Medicaid and all others) as a proxy for SES.

To mitigate issues with propensity score estimates, we coarsened maternal age (eg, $<20$ years, $21-25$ years, 26-30 years and $>30$ years) and our indirect SES measure, the median household income of the mother's zip code (decile indicators). All other variables were categorical and include the mother's race/ethnicity, country of birth, marital and cohabiting status, whether or not this was her first birth, the presence of pre-existing health conditions (non-gestational diabetes and/or hypertension, and/or a previous PTB), the county of residence and the year of the delivery. Our variable selection is guided by the HomVEE standards, which require that the covariates used to balance the treatment and control groups be associated with both treatment status and the outcomes of interest, ${ }^{36}$ and is limited to information available in the data sources.

A critical criterion associated with the HomVEE moderate rating is baseline equivalence, requiring any differences between the treatment and matched-control groups be not statistically significant at the $(\alpha) 5 \%$ level. Consequently, we verified that our models meet this standard for the Health Start Programme population as a whole, and for each subgroup for whom we separately estimated Health Start Programme's effectiveness. Interaction terms were added to the core set of variables described here to achieve balance and meet the HomVEE standard, as demonstrated in tables 1-3, and more fully in the supplemental tables. In meeting this criterion, the present study can successfully replicate a blocked experimental design, based on observable characteristics. In addition, the standardised differences (SDs) for all analyses do not exceed 0.2, a typical cut-off for a 'small' effect size.

\section{Descriptive statistics and baseline equivalence}

We accessed records for 966809 total births in Arizona from 2006 to 2016 for this study. Among these births, 7212 were to Health Start Programme participants. The first two columns of table 1 show the descriptive statistics for these two populations. Compared with all statewide births, Health Start Programme participants were more likely to be younger than 24 years of age, born in Mexico, have Medicaid insurance, and have pre-exiting health risks, and less likely to identify as white or other race/ ethnicity, have an education greater than high school degree or GED, and be married or cohabitating. Among Health Start Programme participants, a majority (59\%) identify as Latina, over $30 \%$ were from a rural border county, $12 \%$ identify as American Indian, $17 \%$ were teen mothers and $11 \%$ had pre-existing health risks. Just $2.6 \%$ identify as black and $1.8 \%$ as Asian/Pacific Islander, together with those for whom race/ethnicity information is missing, comprise the 'other' category for this variable.

These statistics illustrate both the diversity of the Arizona population and the heterogeneity of Health Start Programme participants. While the propensity score explicitly controls for these (observed) differences in identifying the matches in the non-participant population, we take the additional step of implicitly controlling for unobserved potential differences by evaluating the effectiveness of Health Start Programme separately for selected demographic subgroups. Conditioning on these characteristics further limits the potential for selection bias by narrowing the comparisons.

From the 966809 total births, 53948 (unweighted) were identified as matched controls. Baseline equivalence between Health Start Programme participants and their matches is detailed in tables 1-3 and online supplemental table 1 for all variable comparisons by subgroup. The impact of Health Start Programme is measured by the difference in rates for each outcome measure between the treatment and matched control groups, the ATT. ${ }^{37} 38$ All ATTs were estimated in Stata V.14 using the teffects command suite, which, following Abadie and Imbens (2006) takes into account the fact that the propensity scores used to identify the control group are estimated (and not observed) when calculating the SEs and CIs around the difference in rates (ATT) ${ }^{37}$

\section{RESULTS}

Tables 4 and 5 compare the ATT of Health Start Programme participation on LBW, VLBW, ELBW and PTB, across five subgroups. Below, we detail the statistically significant results. All other results were not statistically significant. 


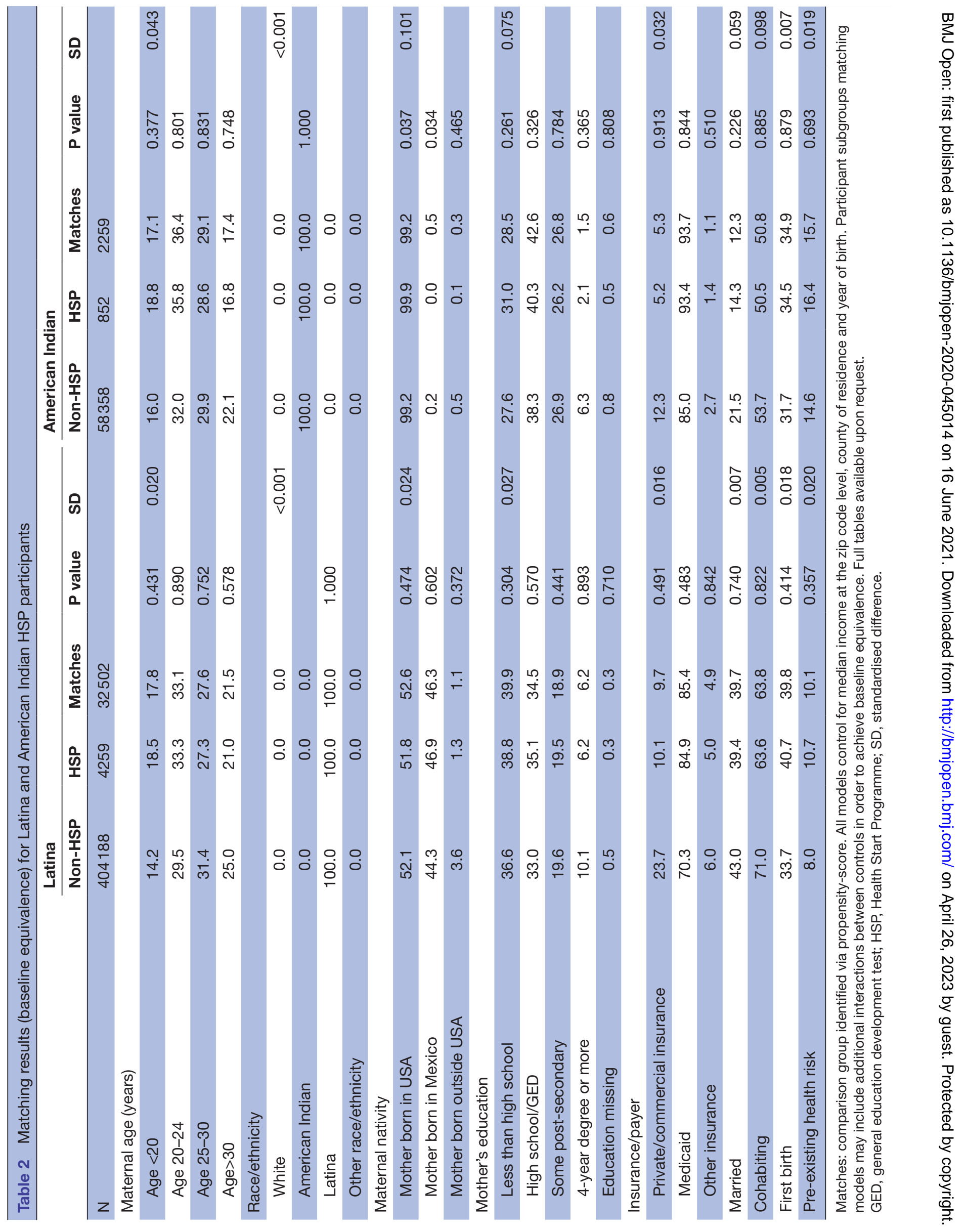


Table 3 Matching results (baseline equivalence) for teen mothers and mothers with pre-existing health risks

\begin{tabular}{|c|c|c|c|c|c|c|c|c|c|c|}
\hline & \multicolumn{5}{|c|}{ Teen mothers (Age $<20$ years) } & \multicolumn{5}{|c|}{ Mothers with pre-existing health risks* } \\
\hline & Non-HSP & HSP & Matches & $P$ value & SD & Non-HSP & HSP & Matches & $P$ value & SD \\
\hline N & 95750 & 1264 & 6810 & & & 79912 & 817 & 2101 & & \\
\hline \multicolumn{11}{|l|}{ Maternal age (years) } \\
\hline Age $<20$ & 100.0 & 100.0 & 100.0 & 1.000 & $<0.001$ & 3.8 & 5.9 & 5.1 & 0.516 & 0.045 \\
\hline Age 20-24 & 0.0 & 0.0 & 0.0 & & & 16.6 & 25.7 & 26.1 & 0.866 & \\
\hline Age $25-30$ & 0.0 & 0.0 & 0.0 & & & 33.1 & 34.9 & 33.8 & 0.639 & \\
\hline Age $>30$ & 0.0 & 0.0 & 0.0 & & & 46.5 & 33.5 & 35.0 & 0.532 & \\
\hline \multicolumn{11}{|l|}{ Race/ethnicity } \\
\hline White & 23.9 & 22.2 & 22.9 & 0.669 & 0.065 & 37.3 & 20.9 & 20.2 & 0.714 & 0.023 \\
\hline American Indian & 9.7 & 12.7 & 12.1 & 0.673 & & 10.7 & 17.1 & 17.5 & 0.845 & \\
\hline Latina & 59.7 & 62.2 & 63.0 & 0.681 & & 40.7 & 55.9 & 56.5 & 0.803 & \\
\hline Other race/ethnicity & 6.6 & 2.9 & 2.0 & 0.123 & & 11.4 & 6.0 & 5.8 & 0.833 & \\
\hline \multicolumn{11}{|l|}{ Maternal nativity } \\
\hline Mother born in USA & 79.7 & 83.2 & 84.8 & 0.286 & 0.043 & 74.4 & 66.8 & 66.2 & 0.793 & 0.014 \\
\hline Mother born in Mexico & 18.3 & 16.1 & 14.6 & 0.295 & & 17.3 & 27.7 & 28.3 & 0.783 & \\
\hline Mother born outside USA & 2.0 & 0.6 & 0.6 & 0.861 & & 8.3 & 5.5 & 5.5 & 1.000 & \\
\hline \multicolumn{11}{|l|}{ Mother's education } \\
\hline Less than high school & 55.3 & 57.6 & 57.3 & 0.876 & 0.043 & 20.1 & 29.4 & 31.4 & 0.381 & 0.044 \\
\hline High school/GED & 36.4 & 34.7 & 35.2 & 0.802 & & 27.2 & 34.5 & 33.5 & 0.676 & \\
\hline Some post-secondary & 7.6 & 7.3 & 6.9 & 0.698 & & 30.2 & 30.0 & 29.1 & 0.705 & \\
\hline 4-year degree or more & 0.0 & 0.0 & 0.1 & 0.267 & & 21.4 & 5.8 & 5.5 & 0.830 & \\
\hline Education missing & 0.6 & 0.3 & 0.3 & 0.989 & & 0.8 & 0.2 & 0.3 & 0.873 & \\
\hline \multicolumn{11}{|l|}{ Insurance/payer } \\
\hline $\begin{array}{l}\text { Private/commercial } \\
\text { insurance }\end{array}$ & 11.6 & 6.0 & 5.4 & 0.493 & 0.027 & 41.5 & 13.6 & 13.6 & 1.000 & 0.073 \\
\hline Medicaid & 84.4 & 90.6 & 91.1 & 0.629 & & 54.8 & 84.1 & 82.9 & 0.506 & \\
\hline Other insurance & 4.0 & 3.4 & 3.5 & 0.913 & & 3.7 & 2.3 & 3.5 & 0.143 & \\
\hline Married & 12.0 & 11.7 & 11.3 & 0.755 & 0.012 & 56.8 & 43.2 & 45.2 & 0.426 & 0.039 \\
\hline Cohabiting & 48.6 & 41.9 & 42.3 & 0.809 & 0.020 & 76.6 & 68.1 & 70.3 & 0.335 & 0.103 \\
\hline First birth & 80.6 & 80.8 & 82.6 & 0.237 & 0.047 & 28.4 & 30.7 & 29.9 & 0.706 & 0.019 \\
\hline Pre-existing health risk & 3.1 & 3.8 & 3.6 & 0.834 & 0.008 & 100.0 & 100.0 & 100.0 & 1.000 & \\
\hline
\end{tabular}

Matches: comparison group identified via propensity-score. All models control for median income at the zip code level, county of residence and year of birth. Participant subgroups matching models may include additional interactions between controls in order to achieve baseline equivalence. Full tables available upon request.

${ }^{*}$ Pre-existing health risks defined as the presence of pre-existing (non-gestational) diabetes and hypertension. HSP, Health Start Programme; SD, standardised difference.

LBW: we found low rates of LBW for all subgroups except among Latina women, with statistically significant lower rates of LBW among Health Start Programme participants who identified as American Indian and participants with a known pre-existing health risk (table 4). Among American Indian mothers, the LBW rate was $2.30 \%$ points lower for Health Start Programme mothers compared with their matched controls. Put differently, the LBW rate was $38 \%$ lower for American Indian mothers, a difference of 20 fewer LBW cases, compared with the control group. The LBW rate for Health Start Programme mothers with pre-existing health risks is $25 \%$ lower (3.06\% points), a difference of 25 fewer cases of LBW, compared with their matched controls. In Arizona, mothers who identify as American Indian and mothers with pre-existing health risks have higher rates of LBW compared with Arizona statewide rates, $5.96 \%$ and $10.41 \%$, respectively, versus $5.52 \%$ statewide (table 6 ).

VLBW and ELBW: in Arizona, all subgroups have higher rates of VLBW and ELBW compared with the statewide rates (table 6). We found a reduction in VLBW and ELBW among all participants, except teens, with significant Health Start Programme's effects among participating mothers who identified as Latina. Among Latina mothers, 

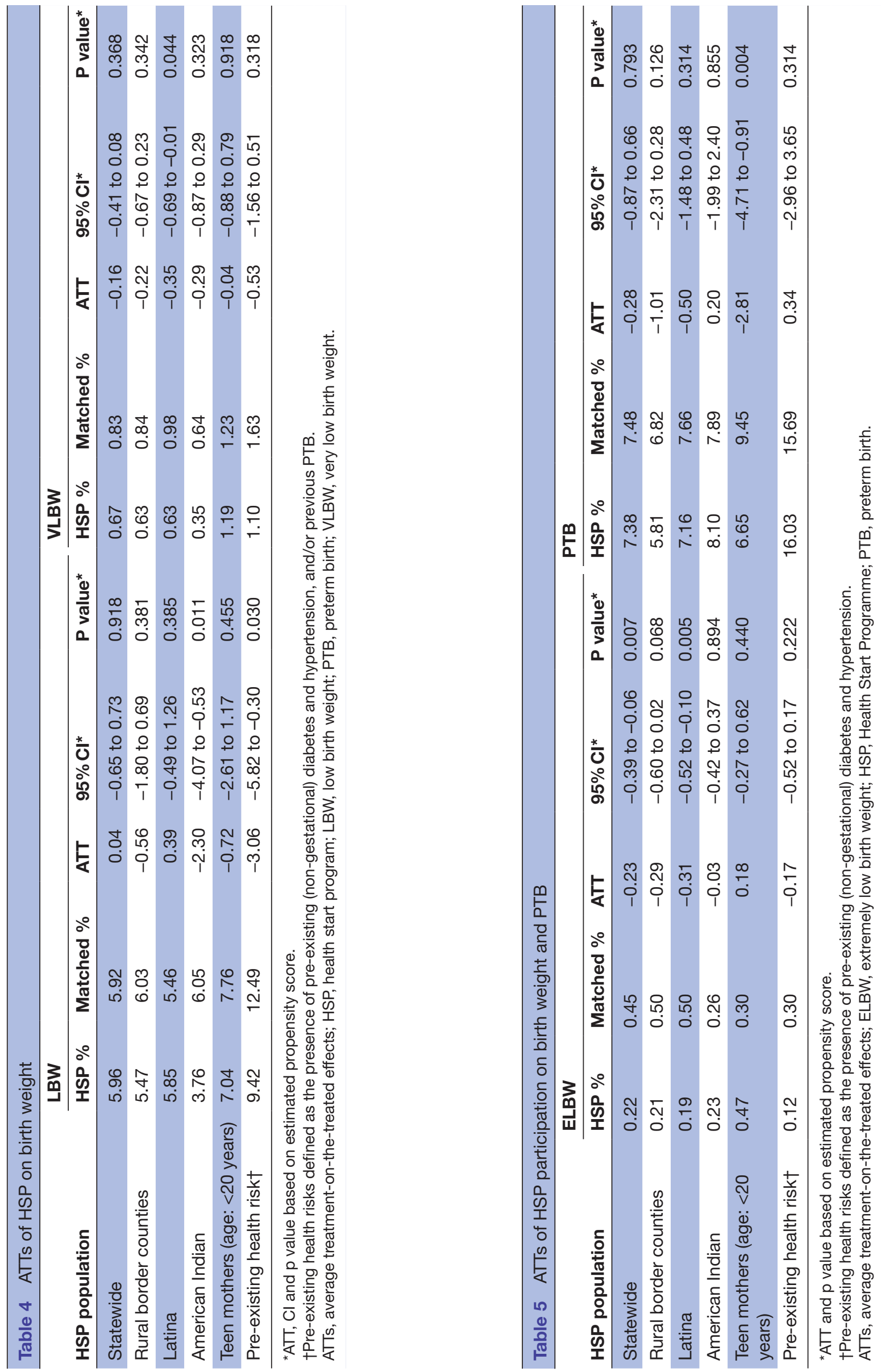
Table 6 Birth outcomes, Arizona population level rates (2006-2016)

\begin{tabular}{llllllll}
\hline & Statewide & Latina & Border & American Indian & Low education & Prior risk & Age <20 years \\
\hline Low birth weight & $5.52 \%$ & $5.45 \%$ & $5.38 \%$ & $5.96 \%$ & $6.24 \%$ & $10.41 \%$ & $6.83 \%$ \\
Very low birth weight & $0.83 \%$ & $0.85 \%$ & $0.85 \%$ & $0.92 \%$ & $0.93 \%$ & $1.82 \%$ & $0.99 \%$ \\
Extremely low birth weight & $0.37 \%$ & $0.40 \%$ & $0.38 \%$ & $0.39 \%$ & $0.41 \%$ & $0.72 \%$ & $0.45 \%$ \\
Preterm birth & $7.97 \%$ & $8.12 \%$ & $6.81 \%$ & $8.88 \%$ & $9.05 \%$ & $16.47 \%$ & $8.66 \%$ \\
\hline
\end{tabular}

the VLBW and ELBW rates were $0.35 \%$ and $0.31 \%$ points lower, respectively, for Health Start Programme mothers compared with their matched controls (tables 4 and 5). Health Start Programme participation is associated with a statistically significant lower VLBW rate $(36 \%)$ and ELBW rate $(62 \%)$ for Latina mothers, which translates to 15 and 13 fewer women having VLBW and ELBW birth outcomes, respectively, compared with Latina women not enroled in Health Start Programme.

PTB: we found reductions in the rate of PTB for all groups except American Indian women and women with a pre-existing health risk $(\mathrm{p}>0.05)$, with statistically significant lower rates of PTB among teen mothers (age: $<20$ years). In Arizona, almost all subgroups have higher rates of PTB compared with the state rate of $7.97 \%$ (table 6 ). Compared with the matched control group, the PTB rate for Health Start Programme teen mothers is 30\% (2.81\% points) lower, equaling 35 fewer cases of PTB.

\section{DISCUSSION}

Consistent with our hypothesis, women enroled in the Health Start Programme prior to giving birth over the study period of 2006-2016 had improved birth outcomes, with the most statistically significant effects among American Indian women, women with pre-existing health risks, Latina women and teen mothers. While these effects appear small, the outcomes are rare occurrences but with large consequences. To illustrate, the $-0.2 \%$-point effect on the ELBW rate for all Health Start Programme participants is small in absolute terms, but the effect represents substantial economic savings. Gilbert $e t a l^{39}$ estimates that the early healthcare costs associated with a surviving ELBW infant is approximately $\$ 202700$, compared with $\$ 1100$ for a healthy infant. The $-0.2 \%$-point effect translates to approximately 16 fewer ELBW cases, translating to an estimated cost savings of $\$ 3.2$ million. This is only an example of the monetary costs associated with these infrequent but expensive outcomes, which, when they occur in already disadvantaged populations such as Health Start Programme participants, are likely to be magnified and multiplied over time.

These findings provide important evidence supporting the efficacy of CHW-led home visiting interventions generally, and specifically CHW's ability to address $\mathrm{MCH}$ equity in ethnoracially and geographically diverse, and socioeconomically disadvantaged populations of mothers and children. ${ }^{40}$ To the best of our knowledge, this is the largest study of a CHW-led MCH home visiting programme on incidence of LBW, VLBW, ELBW and PTB in the USA to date.

Our evaluation is consistent with an earlier evaluation of the Health Start Programme, which found that Health Start Programme participation was associated with a reduction in the likelihood of LBWs. ${ }^{31}$ Our study relies on a substantially larger sample size, longer observational period and a more sophisticated matching methodology. ${ }^{29}$ Moreover, the subgroup analyses are a significant new contribution. Although several rigorous studies of prenatal home visitation programmes exist, most use a combination of licensed health professionals, such as nurses and social workers to achieve outcomes. ${ }^{41-43}$ Unique to the Health Start Programme is the utilisation of CHWs as the sole and primary $\mathrm{MCH}$ interventionist and home visitor. ${ }^{44}$ The evaluation of the Arizona Health Start Programme is one of very few empirical studies in which CHWs are the primary interventionists that operate outside of a clinical setting and not as a member of a primary care or prenatal care coordination team. ${ }^{40-42} 4546$ In the USA, and consistent with our findings, CHWs have contributed to the initiation of any, early, and adequate prenatal care, and decreased incidence of PTB and LBW among health disparate populations. ${ }^{31}{ }^{45-52}$ This study further contributes to CHW effectiveness research in home visitation.

\section{Limitations}

Among the smaller limitations, if Health Start mothers are incorrectly linked to state birth certificate data, attenuation bias is possible, resulting in an underestimate (in absolute value) of the magnitude of the resulting coefficients. Linkage quality measures (eg, per cent match on names, etc) suggest this is not a serious concern. The presence of or interaction of Health Start Programme with other maternal health or home visiting programmes may be another source of bias in our estimated treatment effects. Reviewing available evidence, less than $1 \%$ of Health Start Programme mothers reported participating in similar CHW or home visiting programmes in the state; therefore, to the extent that the matched mothers similarly participate in another home visiting programme, the potential bias likely is toward finding no effect.

More generally, given the uniqueness of Arizona's population and the consequent demographic heterogeneity among Health Start Programme participants, the present analysis may have limited external validity with respect to other states and populations. A larger limitation (common to matching methods in general) is the 
identifying assumption that Health Start Programme participation is fully explained by observable characteristics. Health Start Programme considers social risk factors (eg, domestic violence, lack of family/social support, inconsistent or uncertain employment) as criteria for enrolment. We are unable to observe and account for such factors in this analysis because this information is not available for non-participants (and is rarely collected in large populations in general). At the same time, to the extent that (1) these risks are associated with adverse MCH outcomes, (2) are likely over-represented in the Health Start Programme population and (3) unaccounted for in our control groups, the results presented here likely underestimate a more accurate Health Start Programme's effect.

A related limitation concerns the timing of data collection (at delivery, from the birth certificate) relative to enrolment (prior to delivery). An important identifying assumption of propensity score matching is that the variables used to match are associated with but not affected by treatment status. In the case of controls such as mother's age, race/ethnicity, country of origin and (to a reasonable degree of certainty) pre-existing health conditions, this assumption is easily confirmed. For other controls such as education and insurance, marital and/or cohabitation status, and possible county of residence, it is less certain to be true. For example, a mother may enrol in Health Start Programme without a high school degree and then graduate or complete a GED prior to giving birth. For $86 \%$ of Health Start Programme mothers, the window in which they would be able to make this or other changes is 9 months or less, and for $63 \%$ it is 6 months or less. Insurance status may be the most likely factor to change. To the extent that 'positive' changes (ie, enroling in Medicaid) are associated with positive outcomes, such transitions are likely to lead the Health Start Programme impact to be underestimated, because these mothers will be matched to non-participant mothers 'better off' than they were at baseline.

A final limitation associated with the methodology used here is that we are not able to disentangle which programmatic elements of Health Start Programme (eg, different education or home visit formats) and participant engagement (eg, timing and length of enrolment, and degree of engagement) are associated with the effects we report. While this type of mediation pathway analysis is outside the scope of the present study, it is important to note that we are able to show that Health Start Programme is associated with improved outcomes, however, not why or how.

While these limitations are important to keep in mind, the present study has considerable strengths. The birth certificate data enabled us to account for many important factors associated with birth outcomes at the population level. This includes measures of SES, education and insurance status, which are valuable proxies for many social risks. In addition, the volume of enrolment and birth certificate data and the extended time period over which it was collected made possible the calculation of relatively precise estimates of the effects of the Health Start Programme on low-frequency birth outcomes. Together these results provide valuable high-level evidence of the effectiveness of Health Start Programme.

\section{Implications for public health policy and research}

Our limitations represent important next steps in our research agenda, which, in addition to examining healthcare utilisation and child development outcomes, will look more closely at the Health Start Programme population itself. Programme administrators collect extensive risk and participation information on Health Start Programme participants. We also plan to use Medicaid claims data (over $80 \%$ of Health Start Programme participants are insured by Medicaid) to generate the critical health utilisation and social-risk factors information associated with poor birth outcomes. By comparing programme effects between different participants and implementations, we will be able to address some of these relationships and advance our understanding of the mediating pathways that connect Health Start Programme participation to birth (and other) outcomes.

Several public health entities, including the WHO, the Centers for Disease Control and Prevention, the Institute of Medicine ${ }^{25}$ and the Community Preventive Services Task Force ${ }^{53}$ conclude CHW-centred interventions are effective across disease areas, for example, prevention, screening and management of chronic illnesses such as diabetes, hypertension, cancer and cardiovascular disease, ${ }^{54}$ and across contexts, including community and clinical settings. At the federal level, in 2014, the centres for Medicaid and Medicare-issued guidance to allow states to reimburse for preventive services offered by nonlicensed professionals such as CHWs. Such recognition signals opportunity for expansion of CHW home visiting within MCH systems of care. Our study provides much needed evidence to guide policymakers and practitioners on integration and financing of CHW prenatal home visitation. The Arizona Health Start Programme and its 25-year commitment to strengthening CHW MCH home visiting is a healthcare innovation that can improve birth weight and PTB outcomes among ethnoracially, socioeconomically and geographically diverse mothers and infants of Arizona.

\section{CONCLUSIONS}

A state health department-operated $\mathrm{MCH}$ home visiting intervention that employs CHWs as the primary interventionists may reduce the risk of LBW, VLBW, ELBW and PTB among certain subgroups of women at increased risks for MCH related inequities (ie, American Indian, Latina, women with pre-existing health conditions and teens). Considering the multi-level social and structural determinants of adverse birth outcomes and its impact throughout the life course, results of this evaluation contribute to $\mathrm{MCH}$ home visiting research and policy. Specifically, this study advances CHW effectiveness 
research as sole and primary home visitation interventionists within $\mathrm{MCH}$.

\section{Author affiliations}

${ }^{1}$ Center for Health Equity Research, College of Health and Human Services, Northern Arizona University, Flagstaff, Arizona, USA

${ }^{2}$ Center for Population Science and Discovery, University of Arizona Health Sciences, Tucson, Arizona, USA

${ }^{3}$ Department of Economics, Brigham Young University, Provo, Utah, USA

${ }^{4}$ Center for Biomedical Informatics and Biostatistics, University of Arizona, Tucson, Arizona, USA

${ }^{5}$ Arizona Department of Health Services, Bureau of Women's and Children's Health, Phoenix, Arizona, USA

Acknowledgements We would like to acknowledge the several offices at the Arizona Department of Health Services (ADHS) that have supported this partnership, including the Bureau of Women and Children's Heath, the Health Start Program, the Bureau of Public Health Statistics, the Immunization Program, and Vital Statistics. We are deeply appreciative of their commitment to this study designed to improve the health of women and children of Arizona. We also acknowledge the members of the ADHS Human Subjects Review Board for continued guidance in data sharing and data protection and security. We acknowledge the hundreds of the Health Start CHWs who have worked tirelessly to improve maternal and child health equity among thousands of mothers, infants, and children. We would also like to thank Drs. Lorraine McKelvey and Kimberly McCombs-Thornton for their valuable insights and feedback.

Contributors VP had full access to the identified data in the study and takes responsibility for its integrity. All analyses were conducted on a de-identified (limited) dataset by PW, who is responsible for accuracy of the data analysis. Study concept and design: SS, PW, MB, SR. Acquisition of data: SS, PW, MB, VP, SR. Analysis and interpretation of data: PW, MB, SS, KM, SR, Celaya. Drafting of the manuscript: SS, KM, PW Critical revision of the manuscript for important intellectual content: SS, KM, PW, MC, SR. Obtained funding: SS. Administrative, technical, or material support: KM, DJJ. Study supervision: SS, PW, SR.

Funding This work is supported through an inter-agency contract from the Arizona Department of Health Services. Funding for the study is provided by the Arizona State Lottery through the Arizona Department of Health Services for the time period of July 1, 2017-June 30, 2022. Health Resources Services Administration (HRSA) Maternal, Infant, Early Childhood Home Visiting (MIECHV) provided 17 months of additional federal funding through the Arizona Department of Health Services during the study period. Role of Sponsor: The funding source, Arizona Department of Health Services, worked closely with the authors to design and conduct the study; collection, management, analysis, or interpretation of the data; preparation, review, or approval of the manuscript; and decision to submit the manuscript for publication.

Map disclaimer The depiction of boundaries on the map(s) in this article does not imply the expression of any opinion whatsoever on the part of BMJ (or any member of its group) concerning the legal status of any country, territory, jurisdiction or area or of its authorities. The map(s) are provided without any warranty of any kind, either express or implied.

Competing interests None declared.

Patient consent for publication Not required.

Ethics approval Approved by the University of Arizona Research Institutional Review Board (protocol number: 1701128802) on 25 January 2017.

Provenance and peer review Not commissioned; externally peer reviewed.

Data availability statement At the conclusion of the study, de-identified data may be available upon request.

Supplemental material This content has been supplied by the author(s). It has not been vetted by BMJ Publishing Group Limited (BMJ) and may not have been peer-reviewed. Any opinions or recommendations discussed are solely those of the author(s) and are not endorsed by BMJ. BMJ disclaims all liability and responsibility arising from any reliance placed on the content. Where the content includes any translated material, BMJ does not warrant the accuracy and reliability of the translations (including but not limited to local regulations, clinical guidelines, terminology, drug names and drug dosages), and is not responsible for any error and/or omissions arising from translation and adaptation or otherwise.
Open access This is an open access article distributed in accordance with the Creative Commons Attribution Non Commercial (CC BY-NC 4.0) license, which permits others to distribute, remix, adapt, build upon this work non-commercially, and license their derivative works on different terms, provided the original work is properly cited, appropriate credit is given, any changes made indicated, and the use is non-commercial. See: http://creativecommons.org/licenses/by-nc/4.0/.

\section{ORCID iDs}

Samantha Sabo http://orcid.org/0000-0003-4509-9182

Kelly McCue http://orcid.org/0000-0002-8383-0338

Dulce J Jimenez http://orcid.org/0000-0003-2962-7467

\section{REFERENCES}

1 National Academies of Sciences, Engineering, and Medicine. The root causes of health inequity: Committee on community-based solutions to promote health equity in the United States. Washington, DC: National Academies of Sciences, Engineering, and Medicine, 2017.

2 Krieger N, Van Wye G, Huynh M, et al. Structural racism, historical Redlining, and risk of preterm birth in New York City, 2013-2017. Am J Public Health 2020;110:1046-53.

3 Paneth NS. The problem of low birth weight. Future Child 1995;5:19-34.

4 World Health Organization (WHO). Global nutrition targets 2025: low birth weight policy brief. Geneva: World Health Organization, 2014.

5 Rimer BK. Theory at a glance a guide for health promotion practice. 2nd ed. Bethesda, MD: U.S. Dept. of Health and Human Services, National Institutes of Health, National Cancer Institute, 2005.

6 Martinson ML, Reichman NE. Socioeconomic inequalities in low birth weight in the United States, the United Kingdom, Canada, and Australia. Am J Public Health 2016;106:748-54.

7 Martin JA, Hamilton BE, Osterman MJK, et al. Births: final data for 2017. National Vital Statistics Reports 2018;67:1-50.

8 Health Resources \& Services Administration (HRSA). Child health USA 2014. Rockville: Maternal and Child Health Bureau, 2015.

9 Pineles B. Smoking in pregnancy: from effects to solutions [Dissertation. Los Angeles: University of Southern California, 2013.

10 Thompson JMD, Wall C, Becroft DMO, et al. Maternal dietary patterns in pregnancy and the association with small-for-gestationalage infants. Br J Nutr 2010;103:1665-73.

11 Almeida J, Bécares L, Erbetta K, et al. Racial/Ethnic inequities in low birth weight and preterm birth: the role of multiple forms of stress. Matern Child Health J 2018;22:1154-63.

12 Brewin D, Nannini A. Using a life course model to examine racial disparities in low birth weight during adolescence and young adulthood. J Midwifery Womens Health 2014;59:417-27.

13 Gress-Smith JL, Luecken LJ, Lemery-Chalfant K, et al. Postpartum depression prevalence and impact on infant health, weight, and sleep in low-income and ethnic minority women and infants. Matern Child Health J 2012;16:887-93.

14 Tomita A, Labys CA, Burns JK. Depressive symptoms prior to pregnancy and infant low birth weight in South Africa. Matern Child Health J 2015;19:2179-86.

15 Dolan SM. Interpregnancy interval and congenital anomalies. Am J Obstet Gynecol 2014;210:498-9.

16 Ncube CN, Enquobahrie DA, Albert SM, et al. Association of neighborhood context with offspring risk of preterm birth and low birthweight: a systematic review and meta-analysis of populationbased studies. Soc Sci Med 2016;153:156-64.

17 McEwen BS, Stress MBS. Stress, adaptation, and disease. allostasis and allostatic load. Ann N Y Acad Sci 1998;840:33-44.

18 Russell RB, Green NS, Steiner CA, et al. Cost of hospitalization for preterm and low birth weight infants in the United States. Pediatrics 2007;120:e1-9.

19 Black SE, Devereux PJ, Salvanes KG. From the cradle to the labor market? the effect of birth weight on adult outcomes. $Q J$ Econ 2007;122:409-39.

20 Gueorguieva R, Morse SB, Roth J. Length of prenatal participation in WIC and risk of delivering a small for gestational age infant: Florida, 1996-2004. Matern Child Health J 2009;13:479-88.

21 Kogan MD. Social causes of low birth weight. J R Soc Med 1995;88:611-5.

22 Currie J. Healthy, wealthy, and wise: socioeconomic status, poor health in childhood, and human capital development. J Econ Lit 2009;47:87-122.

23 Balcazar H, Rosenthal EL, Brownstein JN, et al. Community health workers can be a public health force for change in the United 
States: three actions for a new paradigm. Am J Public Health 2011:101:2199-203.

24 Kangovi S, Grande D, Trinh-Shevrin C. From rhetoric to reality-community health workers in post-reform U.S. health care. $N$ Engl J Med 2015;372:2277-9.

25 Pittman M, Sunderland A, Broderick A. Bringing community health workers into the mainstream of U.S. health care. 5. Washington, DC: Institute of Medicine, 2015.

26 Sikka R, Morath JM, Leape L. The quadruple aim: care, health, cost and meaning in work. BMJ Qual Saf 2015;24:608-10.

27 Bodenheimer T, Sinsky C. From triple to quadruple aim: care of the patient requires care of the provider. Ann Fam Med 2014;12:573-6.

28 Lee H, Crowne SS, Estarziau M. The effects of home visiting on prenatal health, birth outcomes, and health care use in the first year of life: final implementation and impact findings from the mother and infant home visiting program Evaluation-Strong start. Washington, DC: Office of Planning, Research, and Evaluation, Administration for Children and Families, US. Department of Health and Human Services, 2019.

29 Sabo S, Butler M, McCue K, et al. Evaluation protocol to assess maternal and child health outcomes using administrative data: a community health worker home visiting programme. BMJ Open 2019:9:e031780.

30 Meister JS, Warrick LH, de Zapién JG, et al. Using lay health workers: case study of a community-based prenatal intervention. $J$ Community Health 1992;17:37-51.

31 Hussaini SK, Holley P, Ritenour D. Reducing low birth weight infancy: assessing the effectiveness of the health start program in Arizona. Matern Child Health J 2011;15:225-33.

32 Rumann S. Health start core training manual: a self-paced manual for CHW staff. Arizona: Arizona Department of Health Services, 2014.

33 Home Visiting Evidence of Effectiveness (HomVEE). Review process: producing study ratings. U.S. Department of Health \& Human Services, 2020. Available: https://homvee.acf.hhs.gov/reviewprocess/Producing\%20Study\%20Ratings

34 Rosener SE, Barr WB, Frayne DJ, et al. Interconception care for mothers during well-child visits with family physicians: an implicit network study. Ann Fam Med 2016;14:350-5.

35 Dehejia RH, Wahba S. Propensity score-matching methods for nonexperimental causal studies. Rev Econ Stat 2002;84:151-61.

36 Caliendo M, Kopeinig S. Some practical guidance for the implementation of propensity score matching. J Econ Surv 2008;22:31-72.

37 Abadie A, Imbens GW. Large sample properties of matching estimators for average treatment effects. Econometrica 2006;74:235-67.

38 Abadie A, Imbens GW. Matching on the estimated propensity score. Econometrica 2016;84:781-807.

39 Gilbert WM, Nesbitt TS, Danielsen B. The cost of prematurity: quantification by gestational age and birth weight. Obstet Gynecol 2003;102:488-92.
40 Pan Z, Veazie P, Sandler M, et al. Perinatal health outcomes following a community health Worker-Supported Home-Visiting program in Rochester, New York, 2015-2018. Am J Public Health 2020;110:1031-3.

41 Roman L, Raffo JE, Zhu Q, et al. A statewide Medicaid enhanced prenatal care program: impact on birth outcomes. JAMA Pediatr 2014;168:220-7.

42 Meghea Cl, Raffo JE, Zhu Q, et al. Medicaid home visitation and maternal and infant healthcare utilization. Am J Prev Med 2013;45:441-7.

43 Roman LA, Raffo JE, Meghea Cl. Maternal perceptions of help from home visits by nurse-community health worker teams. Am J Public Health 2012:102:643-5.

44 Bradley PJ, Martin J. The impact of home visits on enrollment patterns in pregnancy-related services among low-income women. Public Health Nurs 1994;11:392-8.

45 Williams CM, Cprek S, Asaolu I, et al. Kentucky health access nurturing development services home visiting program improves maternal and child health. Matern Child Health J 2017;21:1166-74.

46 Redding S, Conrey E, Porter K, et al. Pathways community care coordination in low birth weight prevention. Matern Child Health $J$ 2015;19:643-50.

47 Poland ML, Giblin PT, Waller JB, et al. Effects of a home visiting program on prenatal care and birthweight: a case comparison study. J Community Health 1992;17:221-9.

48 Coughlin RL, Kushman EK, Copeland GE, et al. Pregnancy and birth outcome improvements for American Indians in the healthy start project of the Inter-Tribal Council of Michigan, 1998-2008. Matern Child Health J 2013;17:1005-15.

49 Brown KK, Johnson C, Spainhower M, et al. Is timing of enrollment associated with birth outcomes? findings from a healthy start program in Kansas. Matern Child Health J 2017;21:25-31.

50 DeAngelis KR, Doré KF, Dean D, et al. Strengthening the healthy start workforce: a mixed-methods study to understand the roles of community health workers in healthy start and inform the development of a standardized training program. Matern Child Health $J$ 2017:21:65-74.

51 Bouye $\mathrm{KH}$. The resource mothers program: how community health workers can reduce low-birth weight among African-American clients in WIC programs. Columbus: The Ohio State University, 2005.

52 Lee E, Mitchell-Herzfeld SD, Lowenfels AA, et al. Reducing low birth weight through home visitation: a randomized controlled trial. $\mathrm{Am} J$ Prev Med 2009;36:154-60.

53 Community Preventitve Services Taskforce. Community guide: community health workers, 2017. Available: https://www. thecommunityguide.org/content/community-health-workers

$54 \mathrm{Kim} \mathrm{K}$, Choi JS, Choi E, et al. Effects of community-based health worker interventions to improve chronic disease management and care among vulnerable populations: a systematic review. Am J Public Health 2016;106:e3-28. 